\title{
Architectural Conservation Proposal of Kashinath Bhaban: A Vivid Example of Colonial Architecture in Bengal
}

\author{
Shirajom Monira Khondker* and Nuzaba Binte Kabir \\ Assistant Professor, Ahsanullah University of Science and Technology (AUST), Dhaka-1208, Bangladesh
}

*Email: arc.monira401@yahoo.com

\section{ARTICLE INFORMATION}

Received: September 6, 2019

Revised: November 10, 2019

Accepted: December 2, 2019

Published online: January 27, 2020

\begin{abstract}
During the Colonial period, Bangladesh with a rich cultural heritage and cultural identity is vividly conveyed and navigated as an image of power, pride and creativity. For this research study, the authors carefully chosen a unique ancient building named "Kashinath Bhaban" of Panam Nagar. Panam Nagar is an old settlement as a part of Sonargaon area of Bangladesh. This edifice abides the evidence to the style and design of Colonial architecture in Bengal. It is absolute that the whole Panam city including the building Kashinath Bhaban play an important role to represent our cultural heritage or our glorious past. Therefore an urban conservation of Panam Nagar is needed. This study concentrates on the proposal for the architectural conservation of the building Kashinath Bhaban of Panam which have precious and research worthy documentation or information. The overall research study conducted here is focused on the demonstration of the possible directions of architectural conservation which is based on the building's plan layout, elevations, sectional details, structure as well as construction materials, decoration and ornamentation. For the architectural conservation of the building, here the authors consider restoration procedure as a conservation technique which will help to represent own belief with historical value and cultural exclusivity to the architecture.
\end{abstract}

\section{Introduction}

\subsection{Colonial Architecture and Panam Nagar}

In Colonial period the Colonial architecture represents a different character to that era. New elements from the western architecture were introduced by the British which were merged with the traditional regional style of the Mughals. In consequence, a new amalgam style arose known as the Indo-British or the Colonial style (Mowla and Reza 2000: 31-58). On the other way, the Colonial architecture meaning a combination style of European and indigenous architecture which is reflected more in the secular civic buildings than those of the buildings of religious character. The Colonial architecture is characterized by these structure-types (Hussain, 2007).

An important feature of Colonial architecture in Bengal is the expansive use of various structuretypes hitherto unknown. However the British-Raj established this Colonial architectural style, the local Zamindars and the Kolkata based merchants famous as baniyas continued this Colonial architectural elegance (Hussain, 2007). For its fanciful and romantic character the style even persists today in the minds of those who love history and tradition. In Bengal, a residential quarter of Sonargaon named Panam Nagar is one of the utmost substantial illustrations of Colonial architecture. It signifies the Indo-British architectural grace with spontaneous architectural ornamental features. They are extraordinary in a sense that nowhere in the whole of Bengal such a large assemblage of residential buildings exists (Rahman, 2007).

Panam Nagar is the ancient city which is a part of Sonargaon area. From early thirteenth century Sonargaon was the administrative center of medieval Muslim rulers of East Bengal and today the area falls under Narayanganj district, Bangladesh. In the late $19^{\text {th }}$ century, during British rule, Panam Nagar was recognized as a trading center of cotton fabrics (Fig. 1). Following Colonial architectural style with motivation derived from European sources, Hindu cloth merchants built their residential houses in Panam Nagar. With respect to location and layout, the Panam's buildings 
are mostly concentrated along the Panam Street. Panam Street, $5 \mathrm{~m}$ wide on the average and $600 \mathrm{~m}$ in length laterally which maximum old buildings of Panam Nagar are intensed, and enclosed by canals (Fig. 2). Presently Panam as a historical property is under the ownership of the Government of Bangladesh. The Directorate of Archaeology is its custodian. Most of the inhabitants in Panam are unauthorized occupants. They are too poor to maintain those properties.

Panam Nagar locality is highly dense with one to three storied attached and detached houses of varying types and sizes. The number of the houses which were erected in the Panam area is counted presently at sixty on both the side of the Panam Street (Fig. 2). Among them fifty-two houses in broken-down and abandoned situation in the settlement have been identified. At present-day, thirty-one houses are persisting on the north side of the road and twenty-one houses on the south. Exact count of buildings according to the number of floors cannot be done due to poor accessibility and precarious condition of structure.

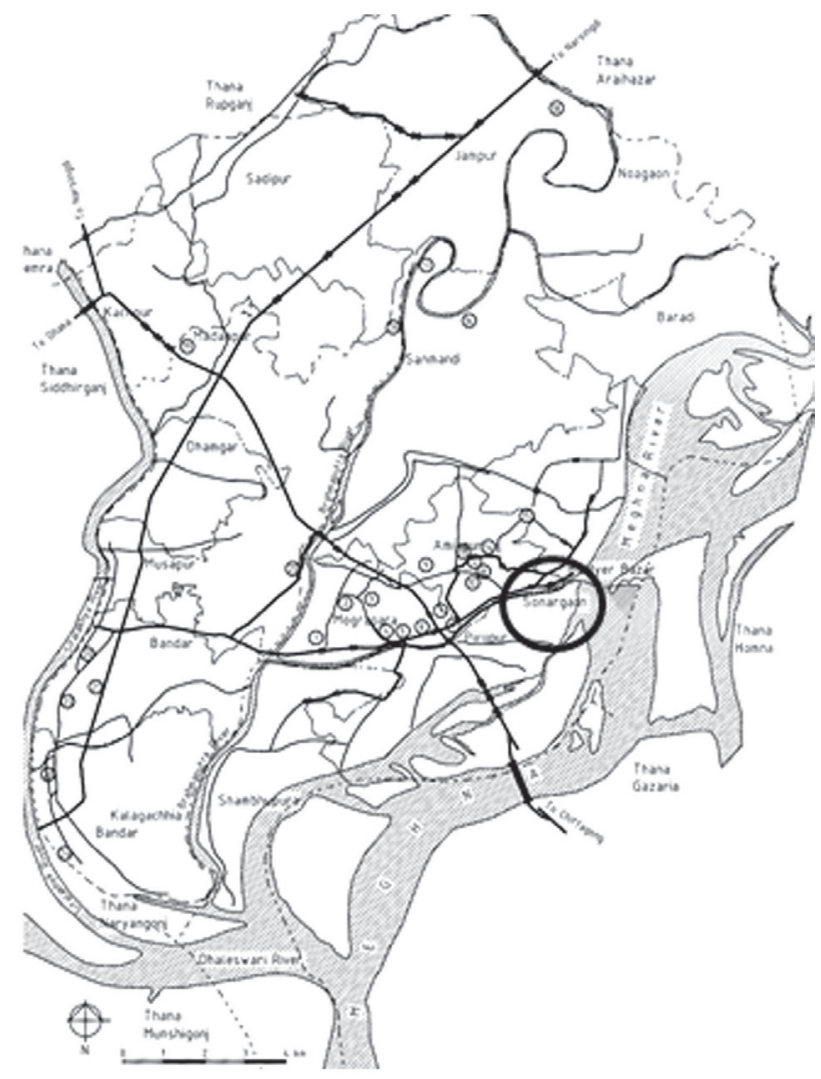

Figure 1: The location map of Panam Nagar in Sonargaon locality. (Source: Shaikh, Z.U., December 2009).

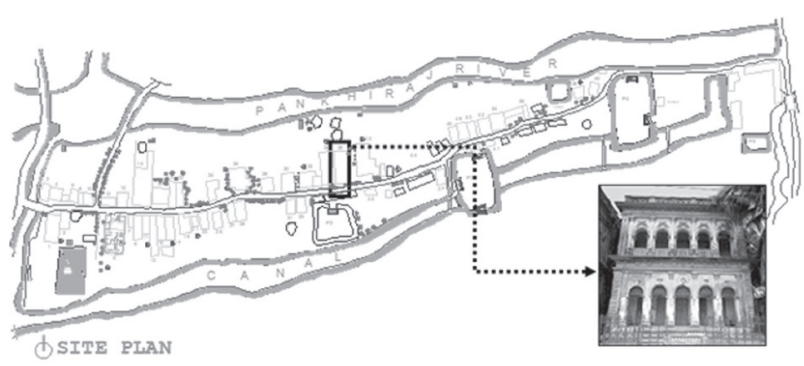

Figure 2: The Existing Master Plan of Panam Nagar showing the sixty buildings and the building no.-38, named "Kashinath Bhaban”. (Source: Khondker, S.M., July 2013).

Among those fifty-two buildings in the Panam Nagar settlement, the building no.-38 and known as "Kashinath Bhaban" (Fig. 2) is a unique, exclusive and exceptional live monument which abides the evidence to the style and design of Colonial architecture in Bengal. That means this edifice exemplifies the architectural characteristics of the Colonial era.

\subsection{Architectural Conservation}

Architectural conservation is the procedure by which individuals or groups effort to protect valued edifices from decay and undesirable alteration. In a broader way, Architectural conservation designates the progression through which the material, historical, and design integrity of humanity's built heritage are sustained through carefully strategic interventions. That is, architectural conservation is maintaining the presence of the past in the present.

Therefore, architectural conservation of cultural heritage may include maintenance, preservation, restoration, reconstruction, and adaptation according to circumstance. For keeping that property in as adjacent to its original condition for as long as possible, it will be generally an amalgamation of more than one of these conservation procedures. Another important aspect of architectural conservation is that it augments contemporary uses in old buildings without destroying their historical value and this ensures the continuance of life and value of the old buildings (Imamuddin, December 1993). Architectural conservation of cultural and historical heritage relates modest proper strategies:

- Nominal intervention;

- Suitable materials and reversible approaches;

- Full documentation of all work undertaken. 
Frequently there are negotiations between preserving appearance, sustaining original design and material properties, and capability to reverse changes. Reversibility is now highlighted so as to diminish difficulties with upcoming treatment, investigation, and use. They must take into account views of the stakeholder, the values and meaning of the work, and the physical needs of the material, in order for conservators to decide upon a proper conservation strategy and apply their professional expertise accordingly.

\subsection{Restoration}

Restoration is one of the degree of intervention in the procedures for architectural conservation. Actually, retaining the remaining fabric of a place to a known previous state by eliminating addition or by reassembling remaining components without the introduction of new material is known as restoration.

The purpose of restoration is to resuscitate the original belief or legibility of the object. Frequently Restoration and re-integration of details and features are constructed upon respect for original material, archaeological evidence, original design and accurate documents. Replacement of missing or decayed parts must assimilate pleasantly with the entire edifice. But this must be distinguishable on close assessment from the original so that the restoration does not falsify archaeological or historical evidence. Therefore, the scrubbing of edifices is also a form of restoration and the replacement of missing decorative elements is another. As in restoration, reconstruction must be based upon accurate documentation and evidence, never upon conjecture.

\section{Objectives}

The main objective of the study of this research paper is to explore and represent the proposal for the restoration, as one of the degree of intervention in the procedures for architectural conservation, of the unique historical building "Kashinath Bhaban" of Panam Nagar which belongs to Colonial architecture in Bengal. It will be presented along with its plan layouts, structure as well as construction materials, decorations and ornamentation details. The objective also includes an in-depth analysis of the architectural conservation considering restoration proposal, and explains its contextual scopes and limitations. Which will help us to find out the impacts and importance of the edifice and construction materials, decorations and ornamentations of that historical building of Panam Nagar as an evidence of our glorious past.

\section{Methodology}

To ensure the eminence of the research study and accumulated proper presentation as well as documentation for the proposal of the restoration as one of the degree of intervention in the procedures for architectural conservation, the authors conducted a field survey on the selected building no.-38 named "Kashinath Bhaban" of Panam Nagar, a locality of historical Sonargaon. This selected historical valued building Kashinath Bhaban have valuable and research worthy edifice, construction materials, decoration and ornamentation details which represent our cultural heritage. The authors conducted a number of field visits to collect or observe the above details. An adequate number of photographs of that unique building have been taken by the authors for the study, as a part of photographic documentation. Some of these have been presented in this paper. For the presentation of the architectural conservation and restoration as a conservation technique on that building the authors have to draw necessary drawings with details regarding the buildings on the basis of field study, as a part of measured documentation. Also these drawings with details have been presented in this paper. For this study, some other sources such as, books, journal articles, encyclopedias, photographs have been accessed.

\section{Contextual Scopes and Limitations of the Architectural Conservation}

Kashinath Bhaban is one of the finest and vivid example of a residential building of colonial period built on the ruins of an earlier Muslim settlement. However as time flies, this historic building requires to represent the concern for cultural rehabilitation as well as thoughtful architectural conversation including meticulous restoration with proper and actual documentation (both measured drawings and photographic documentation) as well as architectural 
information with details not only for its historical value, but also for its unique architectural characteristics.

The building facades of Kashinath Bhaban which need little repair work for reconstruction of the missing attributes, can be easily restored to its original gleam. This is the biggest scopes by the proper restoration work of Kashinath Bhabanas much as possible to its original beauty and splendor, which will represent the culture, history and heritage of this nation to the visitors as a cultural inspiration.

Some portions on there are damaged in a way that, it's not easy to identify its original design and ornamentation's details. Also here chinitikri is used for ornamentation which is not available nowadays. These may be considered as limitations.

\section{Architectural Conservation Strategy}

Architectural conservation strategy for the Kashinath Bhaban will be considered in two steps: firstly, proper and actual documentations (both measured drawings and photographic documentation) will be done carefully; on the other hand secondly, original form space, materials and construction techniques will be restored.

Therefore, restoration proposal is the major issue of our architectural conservation strategy. This restoration work will be included to prepare an authentic intervention proposal for the reconstruction of few missing attributes of all highly ornamented surfaces, floor finish, floral ornamentation details, replacement of wooden beams, doors, windows, and main entrance as well as structural and construction materials details with some others important restoration measures.

\section{Documentation of the building "Kashinath Bhaban"}

In Panam Nagar locality the building "Kashinath Bhaban" is numbered as building no.-38. This building is surviving on the north side of the Panam Street. The facade of this unique live monument is perfectly expressed the desire for simplicity among ornately decorated work.

Documentation of this building will be done by measured drawings and also by photographic detailing. Measured drawings are made by measuring each part of a building and transferring this information into graphic form. Measured drawings include all floor plans and elevations, and detail sections which are all essential in this documentation project. In addition to measured drawing, photography has also a long history and a remarkable role in historic documentation. Photographic documentation archives the existing condition of the buildings by photos.

By means of a documentation process, some important aspects of this unique building are described below including its building typology, layout, structural, construction materials, decoration and ornamentation details along its measured drawings and photographs.

\subsection{Building Typology}

This is a courtyard type building; where on end of the court is lined with the boundary wall (Fig. 3). The concept of this type building is derived from centering on a courtyard. Actually the building activities and layout are organized around the courtyard. The courtyard (Fig. 3) of this building is confined, paved and exposed to sky. Here the courtyard is bounded by verandah on three sides with arched openings. The surrounding verandah acts as corridor and gives access to individual rooms. With arched openings and pilasters, the enclosing walls of the courtyard are extensively outlined.

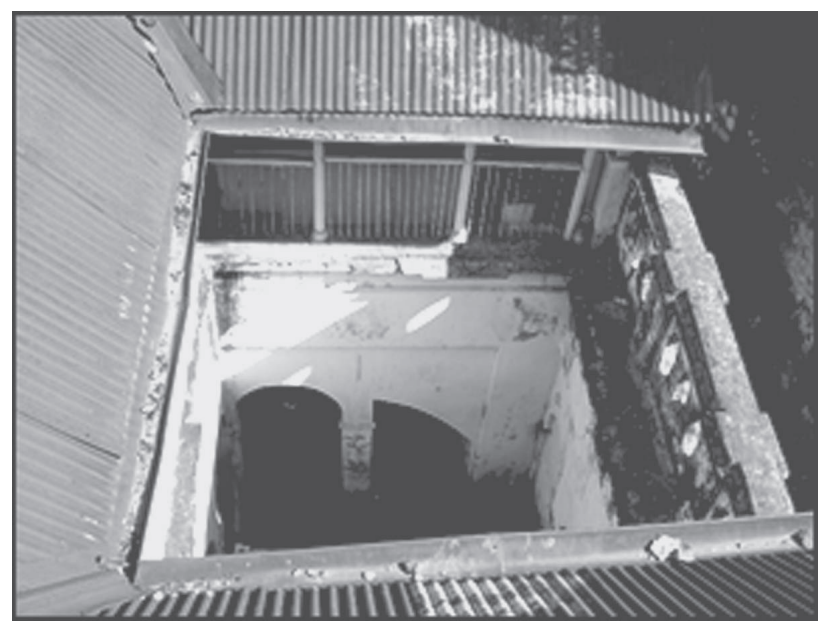

Figure 3: The courtyard of Kashinath Bhaban. (Source: Khondker, S.M., July 2013).

\subsection{Building Layout}

This two storied building is quadrangular in shape and extended in the north-south direction. The depth is 
greater than frontage in this house. The width and length of the building facade is approximately $10.7 \mathrm{~m}$ and $37 \mathrm{~m}$ respectively (Fig. 5. a,b,c). Facades of this building are axially balanced with flanking five openings at each level (Fig. 4). With projected cornice, here the floor levels are articulatedon the outside (Fig. 6). Parapets of this building followed a uniform design and heights with vertical slit openings, curved at the top and bottom (Fig. 7). A transitional space between the inner house and the street is created by the raised plinth and verandah which makes the entry of the building (Fig. 8).

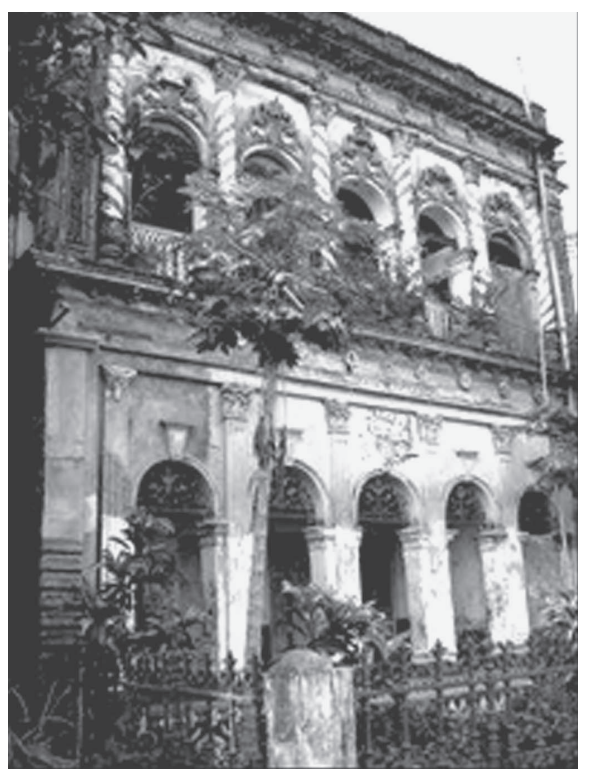

Figure 4: The front facade or street side view of Kashinath Bhaban showing flanking five openings at each level. (Source: Khondker, S.M., July 2013).
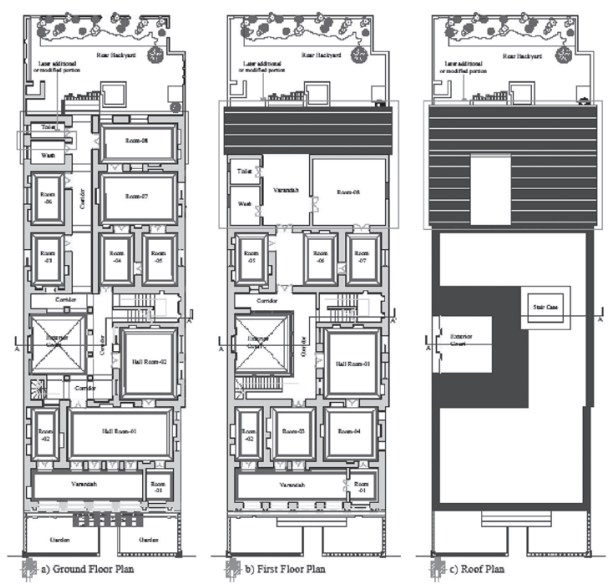

Figure 5: a) Ground floor plan, b) First floor plan, c) Roof plan of Kashinath Bhaban expressed building layout with building structural details. (Source: Khondker, S.M., July 2013 \& prepared by the authors).

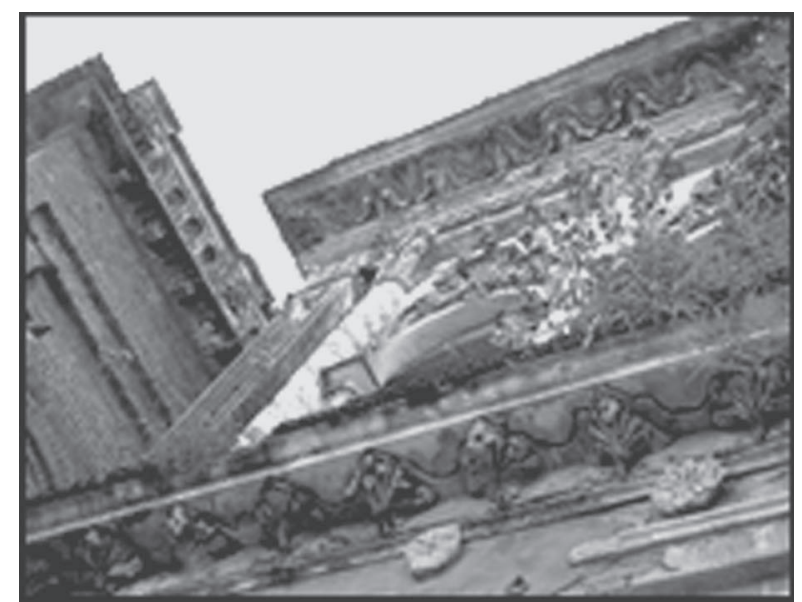

Figure 6: Projected cornice expressed floor levels. (Source: Khondker, S.M., July 2013).

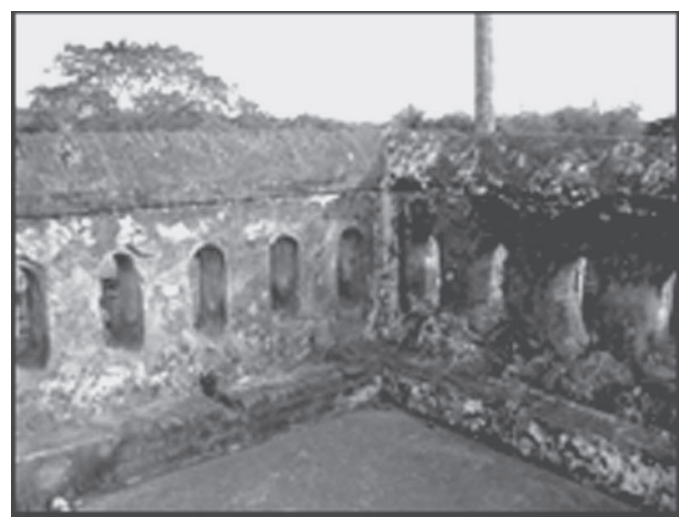

Figure 7: Parapet detailing in the roof. (Source: Khondker, S.M., July 2013).

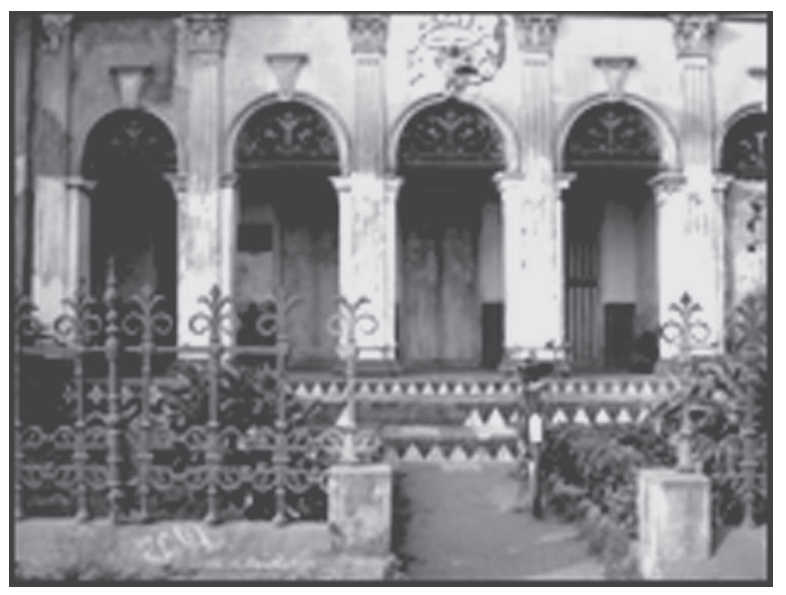

Figure 8: Raised plinth and verandah expressed entry. (Source: Khondker, S.M., July 2013).

The building facades composition were extraordinary with Colonial architectural details. Here the four side 
elevations of the Kashinath Bhaban (according to field study) are given bellow in fig. 9, 10, $11 \& 12$.

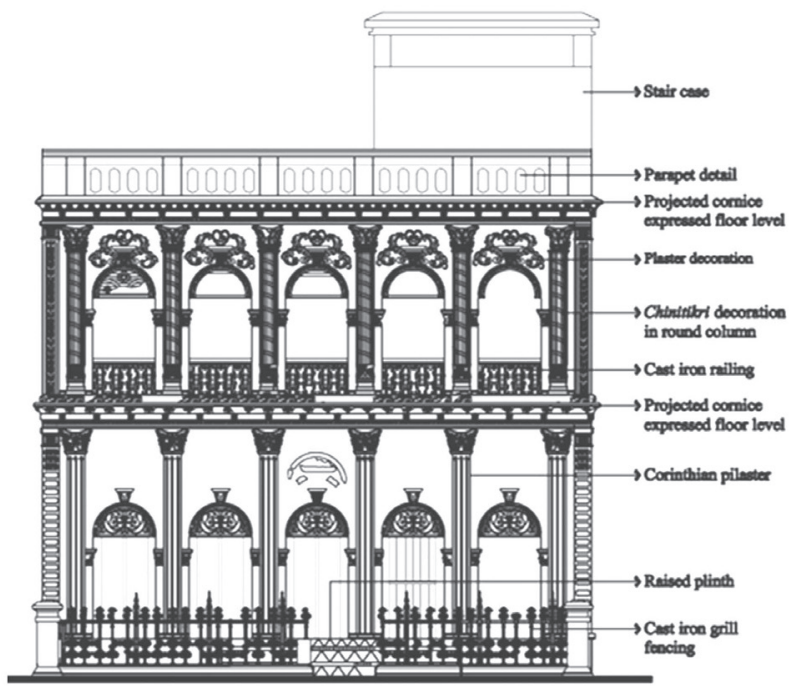

Figure 9: Front (South) side elevation with detailing of Kashinath Bhaban. (Source: Khondker, S.M., July 2013).

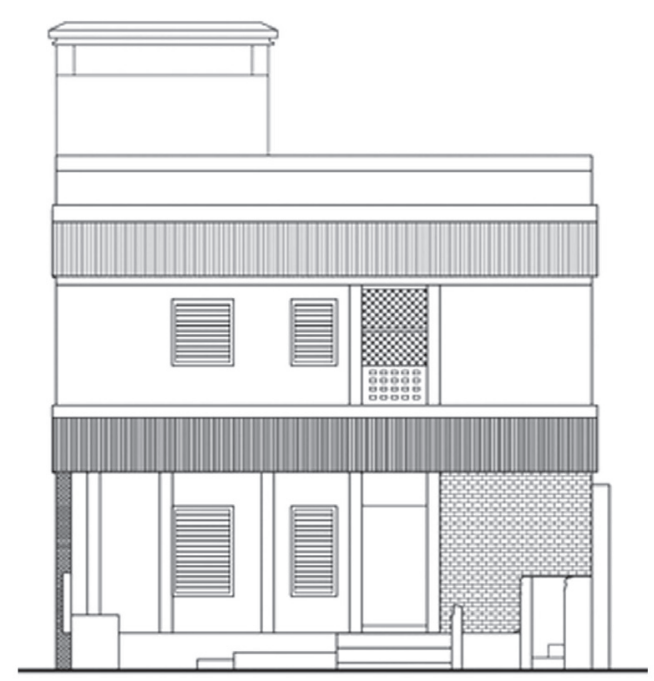

Figure 10: Back (North) side elevation showing later addition $\&$ modification of Kashinath Bhaban. (Source: Khondker, S.M., July 2013).

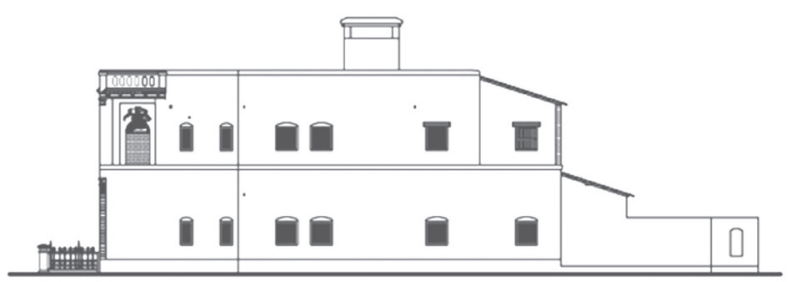

Figure 11: East side elevation of Kashinath Bhaban. (Source: Khondker, S.M., July 2013).

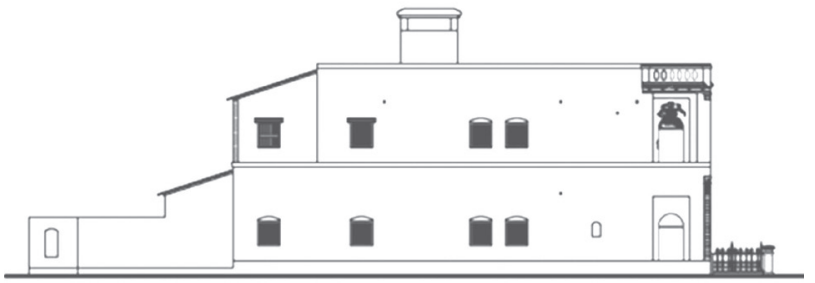

Figure 12: West side elevation of Kashinath Bhaban. (Source: Khondker, S.M., July 2013).

\subsection{Building Structure and Construction Materials}

According to the necessity of surface articulation, the primary construction material was brick which have been modeled in precise form. For facade delimitation bricks are plastered here. The thickness of brick work in walls vary between 50 to $70 \mathrm{~cm}$ (Fig. 5. a,b,c) \& (Fig. 15). Lime mortar has been used primarily for bonding. On the top of upper level verandah, corrugated sheets were placed sloping down towards the courtyard (Fig. 3) \& (Fig. 15). In facade design and interior ornamentation plaster decoration have been extensively applied (Fig. 13). Here as a common decorative element, fabricated wooden doors and windows molded with plaster were also applied. Cast iron brackets, ventilators, window grills, railings, balusters had been extensively used. Ornamentation was made by lime surki and plaster (Fig. 13). In the columns of the front facade for decoration with broken china locally known as chinitikri work has been done (Fig. 13). Decorative colored broken tiles were used on the step riser in front of the entrance verandah (Fig. 14). Structural details will be clear by a section through inner courtyard and stair case (Fig. 15).

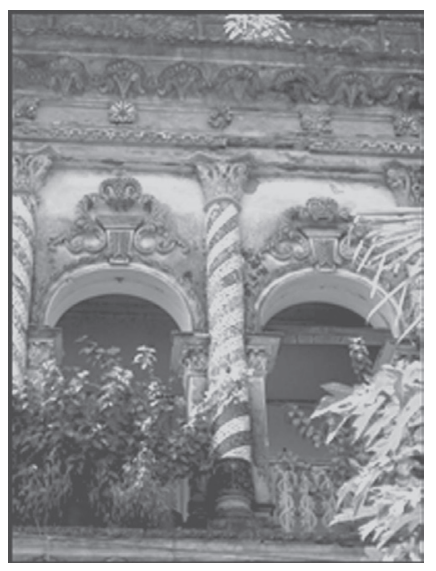

Figure 13: Plaster decoration and chinitikri work of the front facade. (Source: Khondker, S.M., July 2013). 

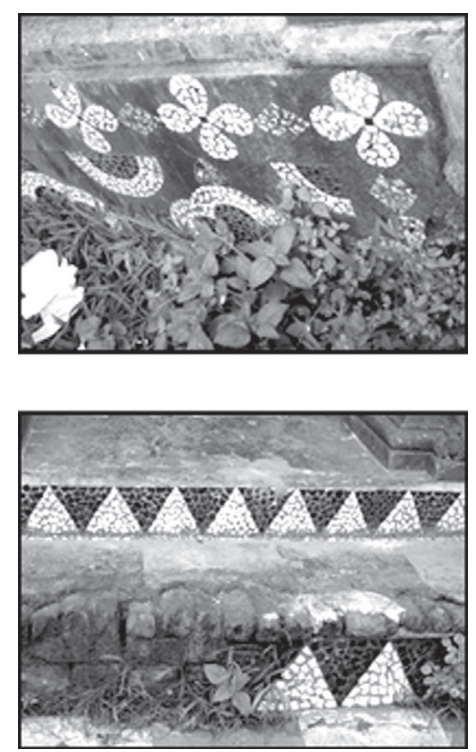

Figure 14: Use of decorative colored broken tiles on the step riser. (Source: Khondker, S.M., July 2013).

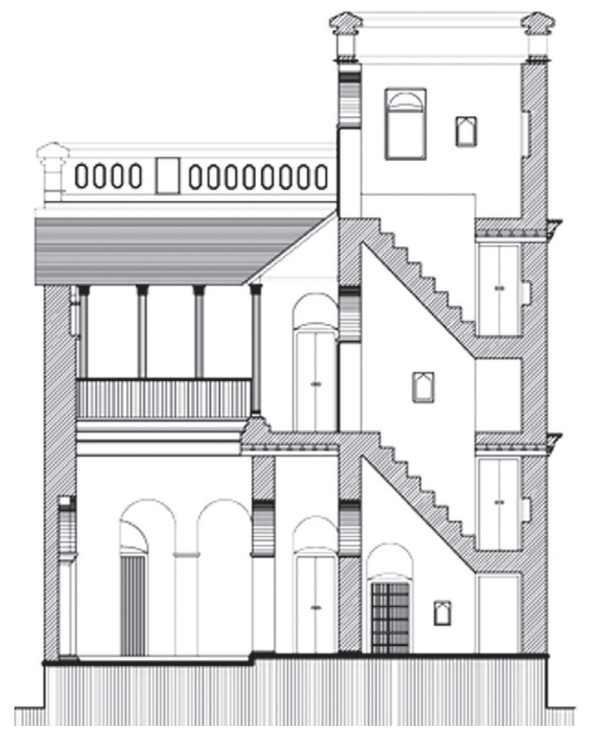

Figure 15: Section - AA' through the inner courtyard and stair case. (Source: Khondker, S.M., July 2013).

\subsection{Building Decoration and Ornamentation}

The ornamentation of the "Kashinath Bhaban" as an example of the colonial building of Panam Nagar is unique through combination of diverse kinds of ornamental form and motifs from several sources. Through the decorations on plinth and floor projection, door and window openings, pillars and pilasters, space between the arch and the roof, cornice and parapet, railing, bracket, building edge and ceilings etc., here the ornamentations of this building are expressed accurately. The plinth of this building is fairly raised from the Panam Street which has neat cement finish (Fig. 14). Decorative colored broken tiles were used on the step riser in front of the entrance verandah or raised plinth (Fig. 14).

The emphasis of the facade configuration is formed by the design of the entrance of this building. The front facade of this building was articulated by round columns with Corinthian capital in the upper floor (Fig. 17) and Corinthian pilaster in the ground floor (Fig. 16), semi-circular arches with pediments and various other decorative elements. The upper floor columns in the exterior facade have chinitikri decoration consisting of dark color spiral band in a distinct pattern (Fig. 17). For the support of the upper floor verandah roof structure, where corrugated sheets were placed sloping down towards the courtyard, the painted cast iron columns are used (Fig. 18). The pillars, columns and pilasters are all designed with well-defined base, shaft and capital with tremendous decorative elements (Fig. 16, 17 \& 18). Corner of the building is emphasized with decorative floral treatment (Fig. $19 \& 20$ ).

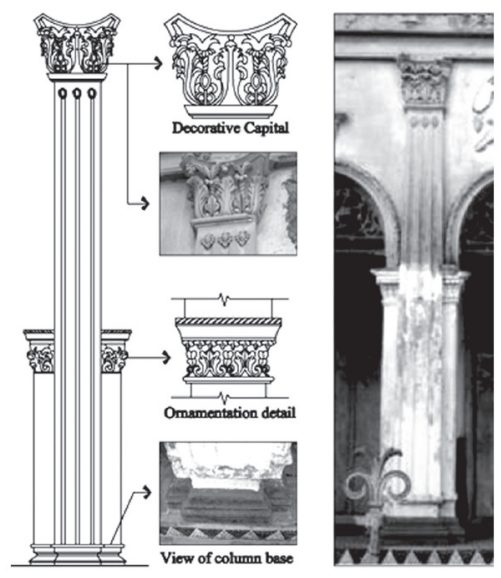

Figure 16: Corinthian pilaster (ground floor) with decorative capital, shaft \& base. (Source: Khondker, S.M., July 2013 \& prepared by the authors).

Regular and simple doorways are noticed here and windows are considered with semi-circular arches bounded in a rectangular or square frame. Closed window, blind arches and shuttered doors create a noticeable tendency to illusionist representations. To express a local identity, indigenous floral pattern are used entirely at the apex of the semi-circular arches (Fig. 21, $22 \& 23$ ).

The use of cast iron decoration in the arch opening on both floors is derived from English neo- 
classical buildings. In this building cast iron brackets, ventilators, window grills, railings, balusters had been widely used with outstanding floral ornamentation (Fig. 21, 22 \& 23). Parapets followed a uniform design and heights with vertical slit openings, curved at the top and bottom (Fig. 24). True to the style, railings, key-stones, column capital, base etc. have been thoroughly decorated.

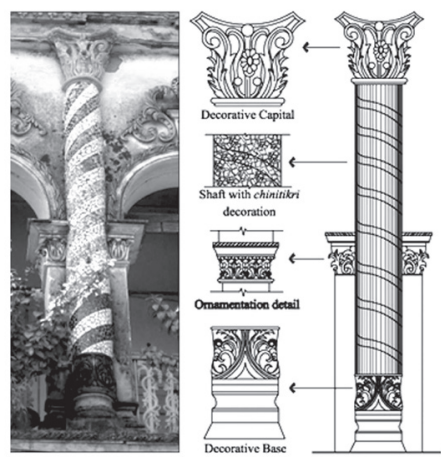

Figure 17: Round columns with Corinthian capital (upper floor) with decorative capital, shaft \& base. (Source: Khondker, S.M., July 2013 \& prepared by the authors).

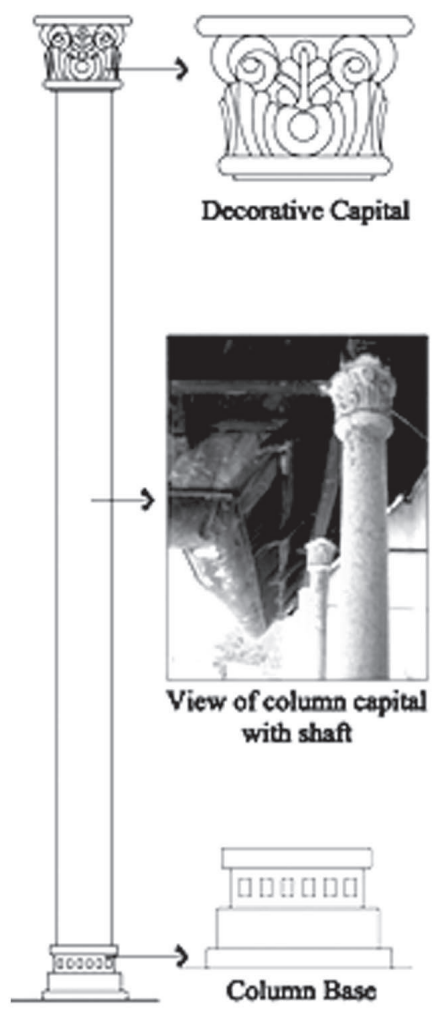

Figure 18: Use of painted cast iron column in the upper floor verandah with decorative capital, simple shaft and base. (Source: Khondker, S.M., July 2013 \& prepared by the authors).

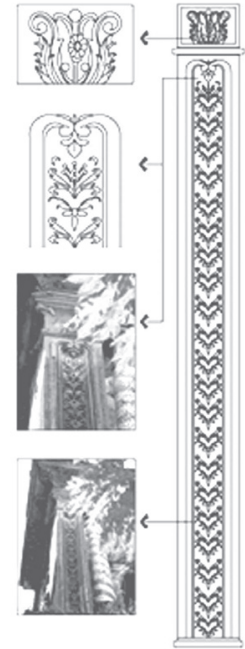

Figure 19: Corner of the building with floral decoration. (Source: Khondker, S.M., July 2013 \& prepared by the authors).

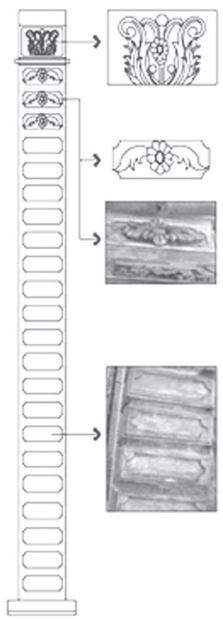

Figure 20: Corner of the building with floral decoration. (Source: Khondker, S.M., July 2013 \& prepared by the authors).

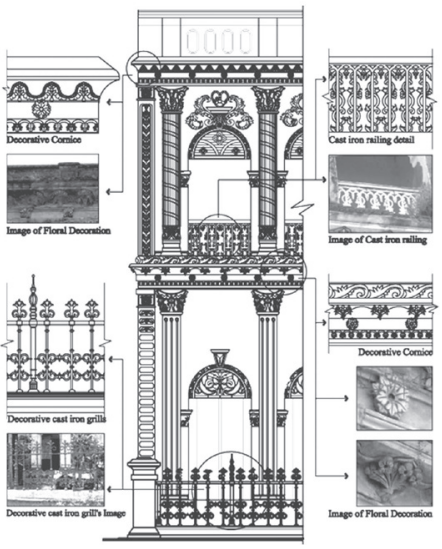

Figure 21: Architectural decoration \& ornamentation details of Kashinath Bhaban. (Source: Khondker, S.M., July 2013). 


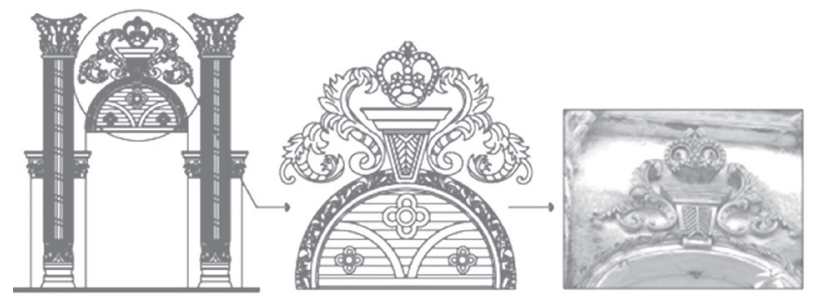

Figure 22: Decorative arch with lime surki \& plaster. (Source: Khondker, S.M., July 2013).

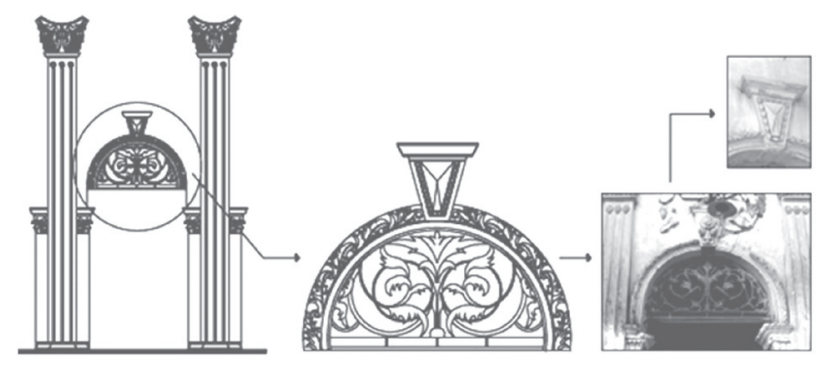

Figure 23: Cast iron decorative arch in doorway. (Source: Khondker, S.M., July 2013).

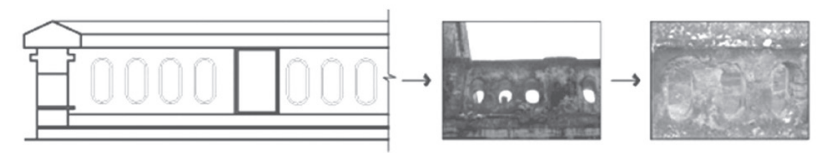

Figure 24: Parapet details with vertical slit openings, curved at the top and bottom. (Source: Khondker, S.M., July 2013).

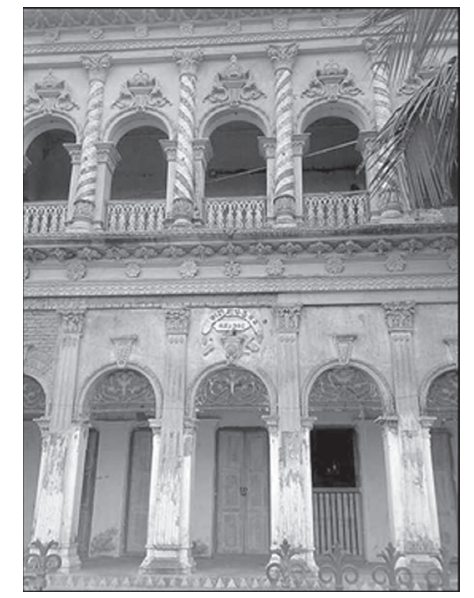

Figure 25: At present, front view of Kashinath Bhaban. (Source: Photograph of 2016 by authors).

\subsection{Present Condition of the Building}

At present existing interior building condition is good for living after reconstruction of the building. But the condition of door, window, and ornamentation of exterior facades is gradually destroyed for lack of preservation (Fig. 26). Recently the archeology department of government of Bangladesh, as a part of taking an action in preservation process, colored this historical building "Kashinath Bhaban" into Pink color (Fig. 25). This has an impact in destroying the originality of the structural, materials, and architectural ornamentation details gradually, which were the historical and socio-cultural evidence of our past.

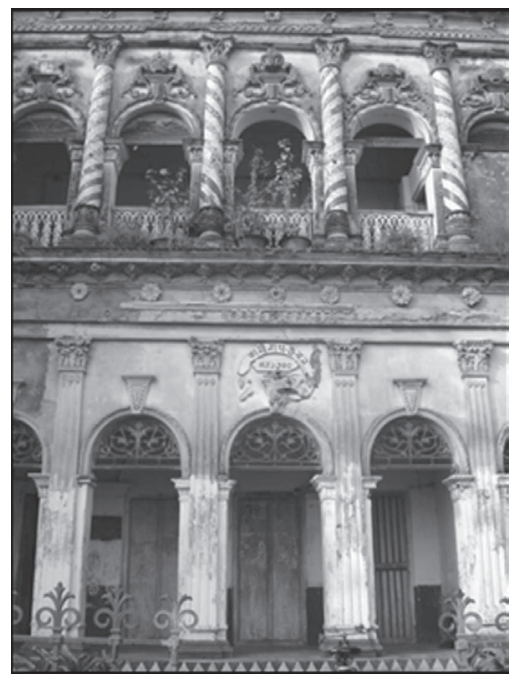

Figure 26: Previous front view of Kashinath Bhaban. (Source: Photograph of 2006 by authors).

\section{Restoration Proposal}

Various steps of restoration works include:

1) In any building, the first step for the restoration, as one of the degree of intervention in the procedures for architectural conservation, is a sensitive assessment of its history and merits through literature and archival research. Therefore, it is necessary to find out the original building layout with furniture details, patterns etc. of the Kashinath time period and need to keep its original reflections in the restoration work. (In this research paper all information, documentations are presented based on the field study in 2006).

2) The goal of the rehabilitation as well as restoration proposal is to retain the original use in all parts. But for this historical building "Kashinath Bhaban", it is not possible to retain the original use and it should be better to adapt re-use for keeping the building alive. Therefore, after the restoration work, the building will be returned to a unique monument portraying the glorious past of the sarders and even a space will be dedicated for archiving of the created documents 
during conversation process, for making it accessible to be used in future research or reference material for any conservation projects.

3) The next step that will be taken in this restoration proposal is de-plastering of all interior and exterior walls that were plastered with cement mortar to expose the original masonry wall plastered with lime mortar (Fig. 27). De-plastering will be done primarily to ensure the structural stability of all masonry wall which will help us to prepare an authentic intervention plan.
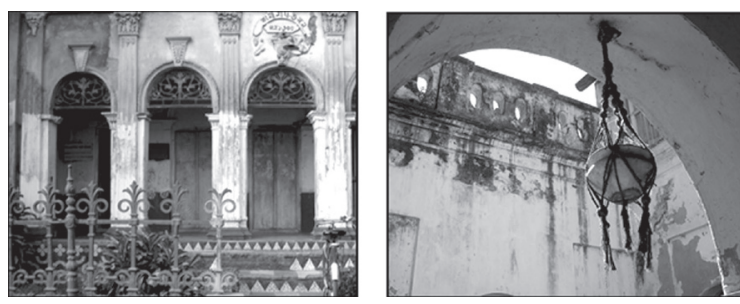

Figure 27: Exterior and interior walls of Kashinath Bhaban that is plastered with cement mortars is need to de-plaster. (Source: Photographs taken by the authors).

4) Wet wall or dampness is a common problem in old buildings. To prevent the rising damp in properties, it will be considered to insert a new physical membrane damp proof course (DPC) into the existing wall (Fig. 28).

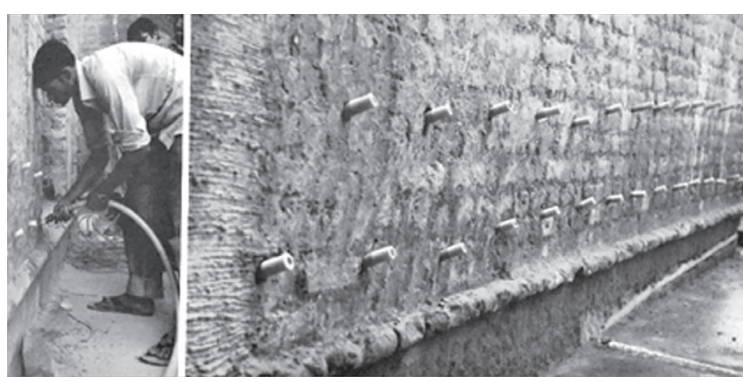

Figure 28: An example of insertion of damp proof course (DPC) into the existing wall. (Source: Ahmed, 2015).

5) To restore the original morphology of the building, it is necessary to remove of all the new developments including extension or modified portion of new construction (Fig. 29).
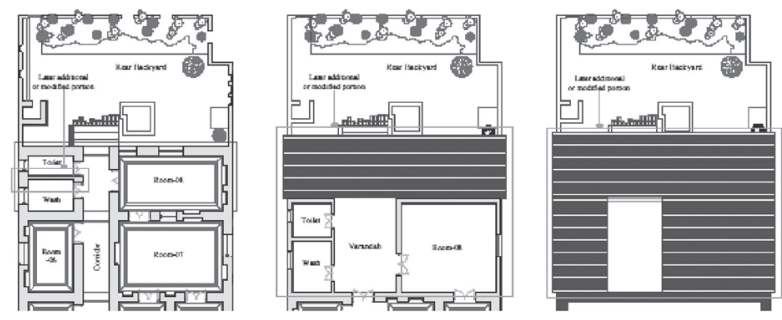

Figure 29: Partial plan with extention or modified portion of new construction. (Source: Field Survey \& prepared by the authors).
6) The growth of several strangler figs in the exterior and interior masonry walls or other parts of the building (Fig. 30) should be removed properly.
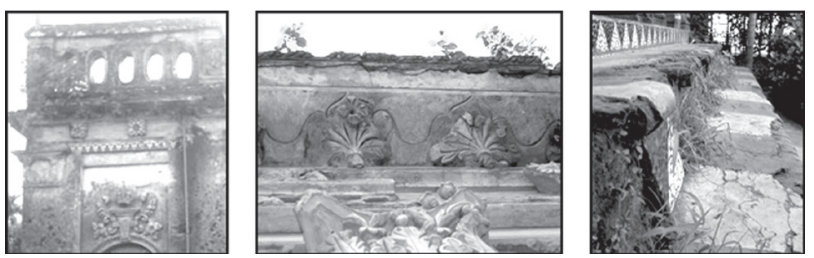

Figure 30: Growth of several strangler figs in the building. (Source: Photographs taken by the authors).

7) Repairing of cracks should be done in proper way which are found in the Kashinath Bhaban building.

8) An authentic intervention proposal measured and photographic documentation for the reconstruction of few missing attributes (Fig. 31, 32, 33, 34, 35, 36 \& 37 ), such as cast iron railing, door and window panel, steps, floor pattern, chinitikri and floral ornamental details should be done accurately.
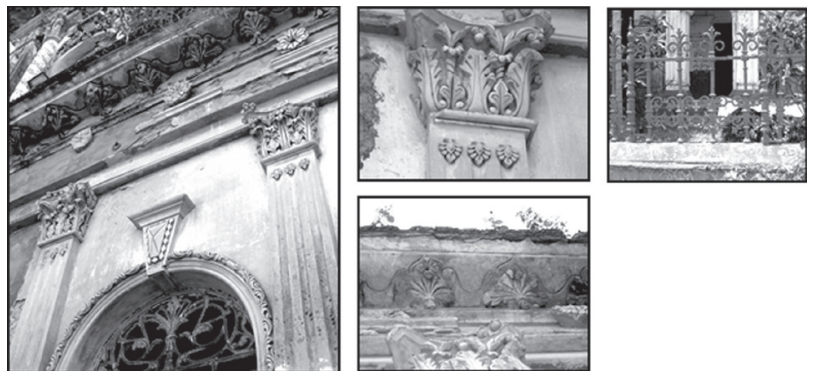

Figure 31: Some missing attributes, such as floral ornamentation, cast iron railing etc. (Source: Photographs taken by the authors).

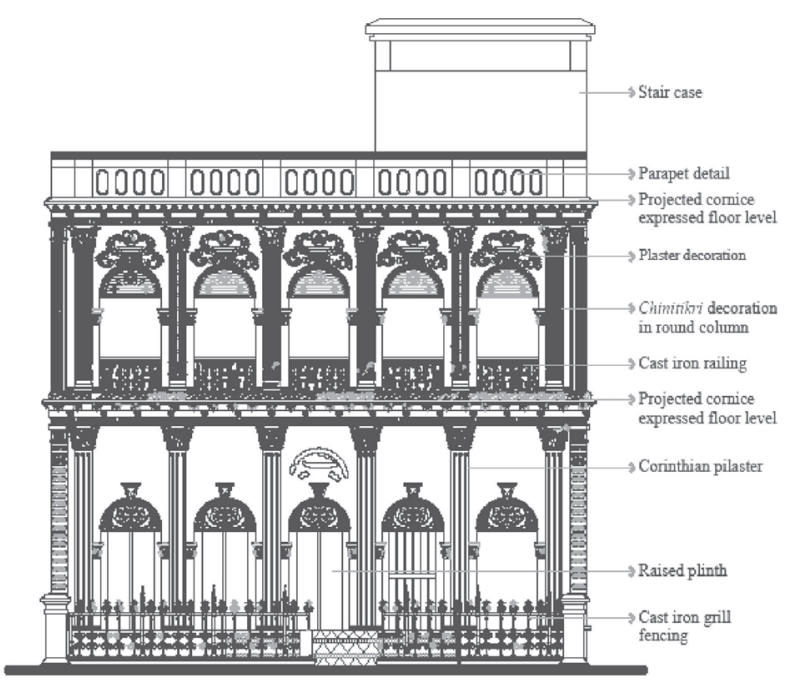

Figure 32: Front elevation with some missing attributes, such as floral ornamentation, cast iron railing, steps etc. through restoration proposal. (Source: Field Survey \& prepared by the authors). 

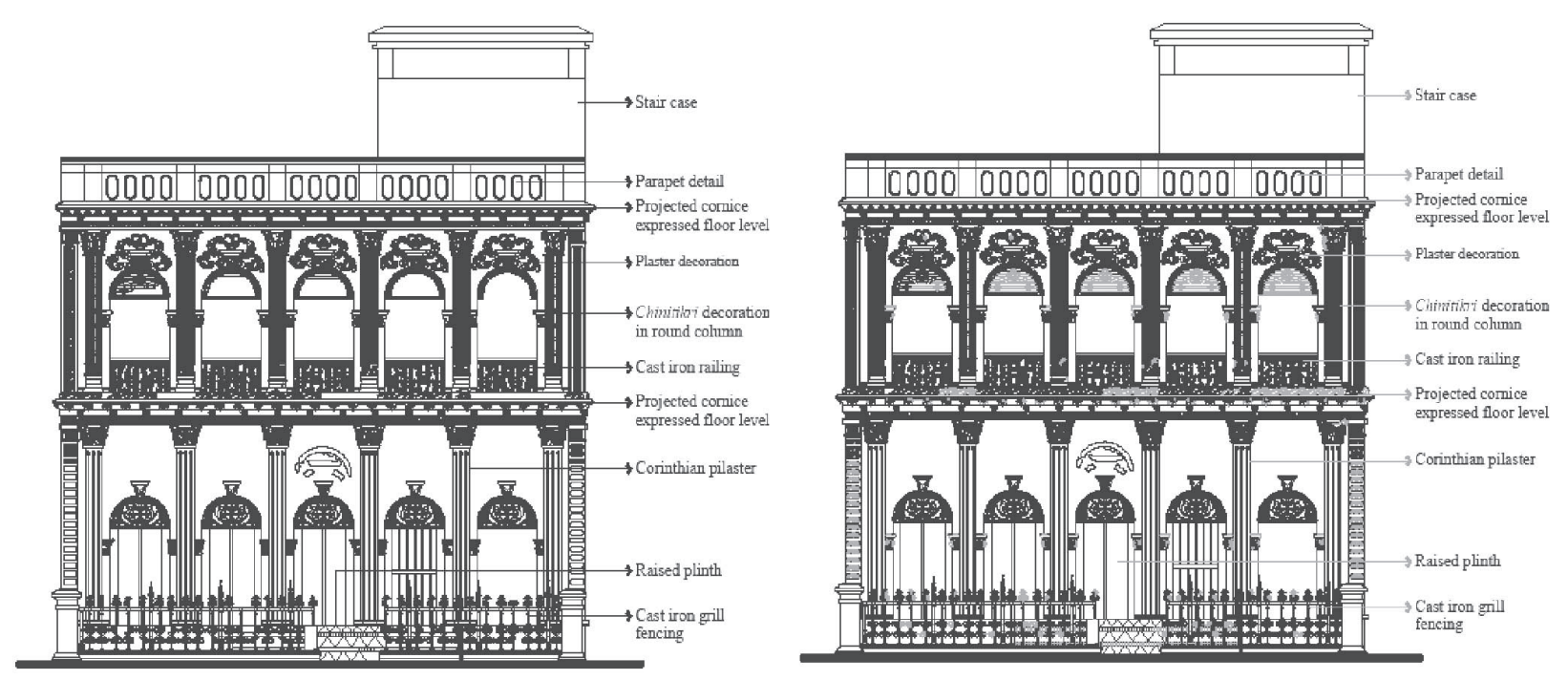

Figure 33: Comparison images of the front elevation of Kashinath Bhaban between existing and through restoration proposal. (Source: Field Survey \& prepared by the authors).
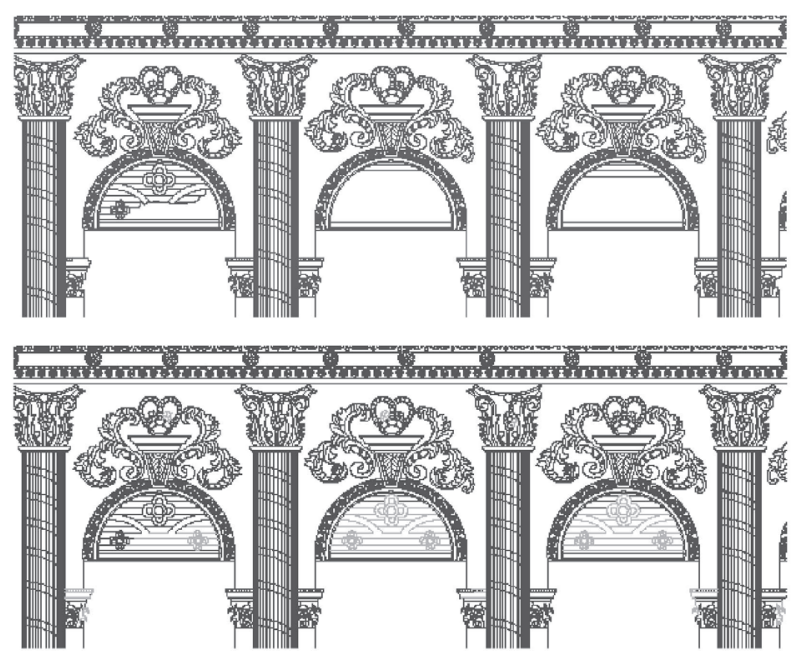

Figure 34: Comparison images of the Partial elevation with some missing floral ornamentations $\&$ decorations between existing and through restoration proposal. (Source: Field Survey \& prepared by the authors).
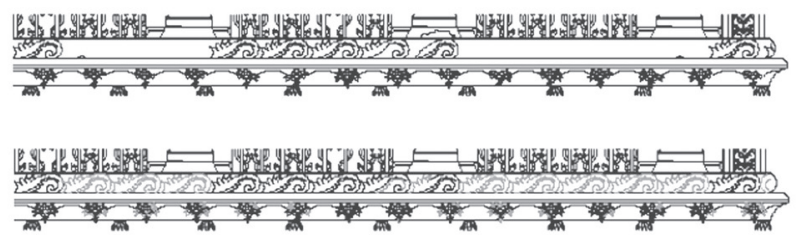

Figure 35: Comparison images of the Partial elevation with some missing floral ornamentations \& decorations of the projected cornice between existing and through restoration proposal. (Source: Field Survey \& prepared by the authors).

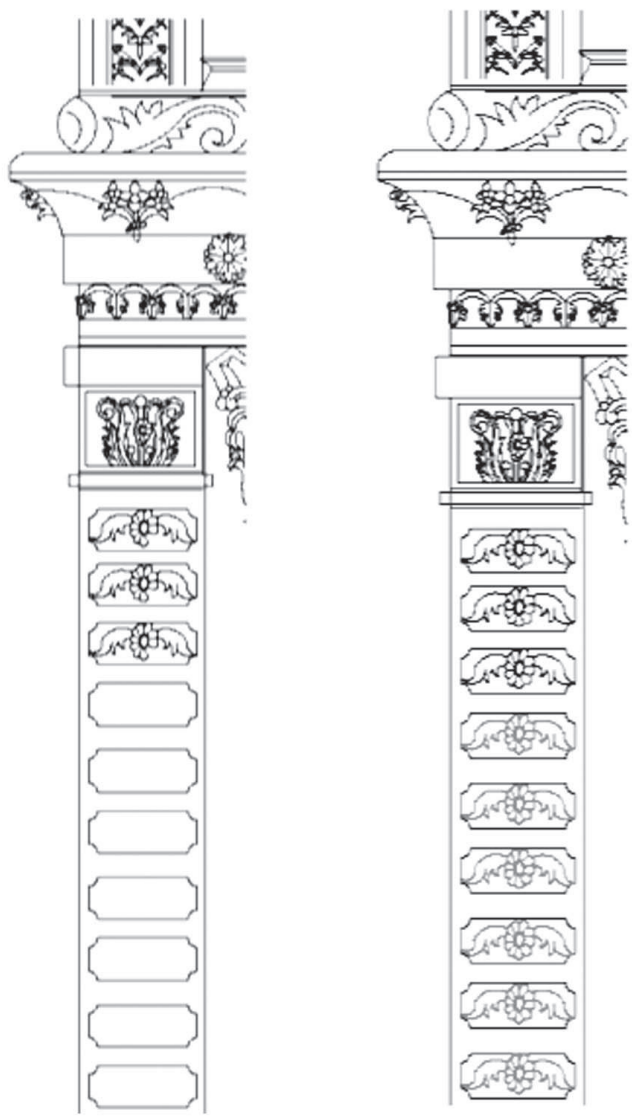

Figure 36: Comparison images of the Partial elevation with some missing plaster decorations of the edge column between existing and through restoration proposal. (Source: Field Survey \& prepared by the authors). 


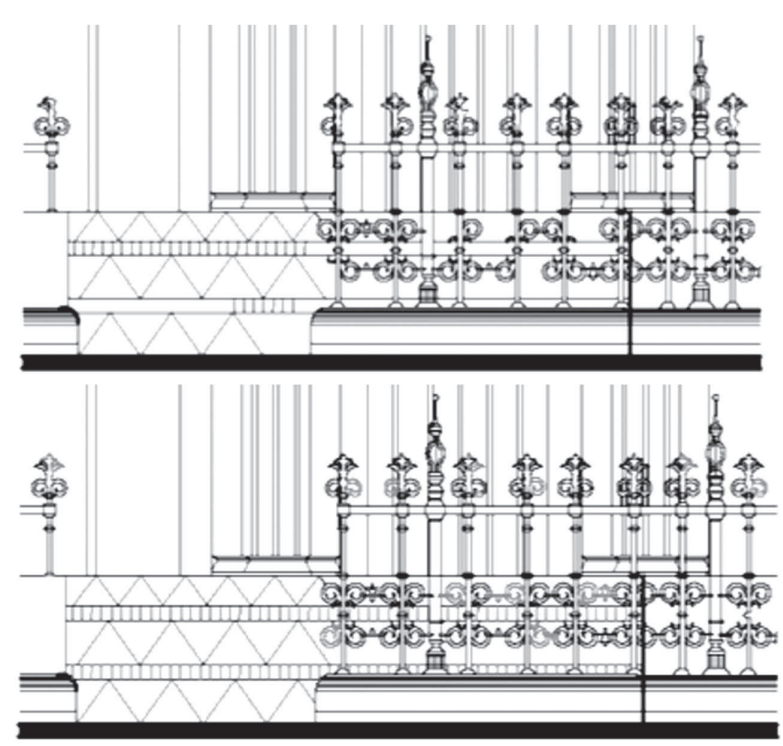

Figure 37: Comparison images of the Partial elevation with some missing floral ornamentations $\&$ decorations of the cast iron between existing and through restoration proposal. (Source: Field Survey $\&$ prepared by the authors).

9) Through the authentic intervention proposal for the restoration work as conservation technique, the missing detailing of the entry facade above the arch could not recognized or documented properly by the authors (Fig. 38). Therefore, it should be restored by the proper investigation from the historical past.

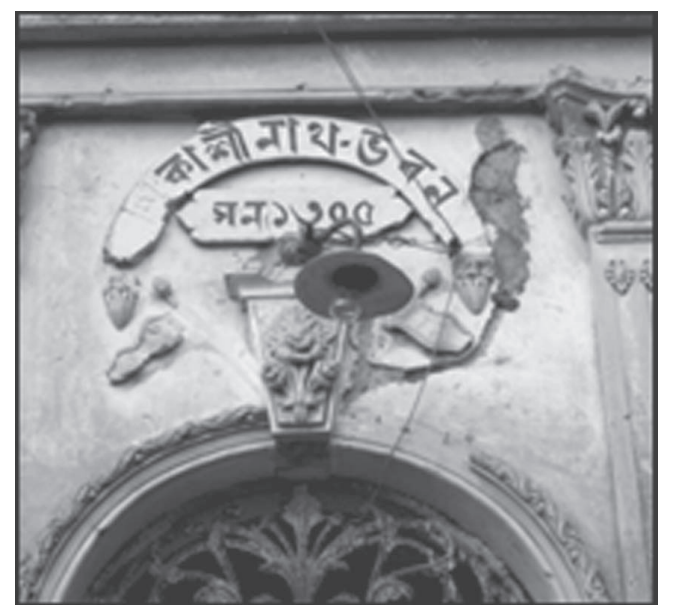

Figure 38: Some missing attributes could not recognized. (Source: Photograph taken by the authors).

\section{Conclusion}

It is apparent from the above mentioned discussion that the colonial architecture established in Bengal, had a uniqueness of its own. As a reflection of Colonial architecture, the unique building named "Kashinath Bhaban" of the ancient Panam Nagar settlement is certainly made a profound influence to the sociocultural antiquity and heritage of Bangladesh. This building of Panam with its structure and materials, decoration and ornamentation is unique which make a strong and glorious image of our past. Presently, this building of Panam Nagar is striving to survive among the face of contemporary developments, climatic adversaries, misuse and scarcity.

On the above circumstances an authentic representation of the restoration, as one of the degree of intervention in the procedures for architectural conservation, with precious documentation on this unique historical building named "Kashinath Bhaban" of Panam Nagar is topmost need. In this regard the authors try to represent a research worthy presentation as well as documentation (based on the field study) and contextual restoration proposal for the architectural conservation of this unique building of Panam Nagar. This proposals of the authors for the restoration, as one of the degree of intervention in the procedures for architectural conservation, will be considered as a part of the urban conservation proposal of the Panam Nagar. Further, which can be recycled to earn revenue by the tourists and also will help the present and future generation to tell our true socio-cultural historical past.

\section{References}

Ahmed, A. S. M., (2015). Unfolding the Past: Conservation of Baro Sardar Bari, Youngone Corporation.

Akhter, S., (2004). Panam Nagar, The Ancient City of Bengal: In Search of Continuity in Tradition, [Unpublished] M. Arch thesis at Carleton University, Ottawa, Canada. The author had been the local supervisor of the thesis, in Bangladesh.

Husain A. B. M., (1997). Sonargaon-Panam: A Survey of Historical Monuments and Sites in Bangladesh, Rashid, M. H. and Chowdhury A. M. (Ed.) published by Asiatic Society of Bangladesh, Dhaka: 103-133.

Husain A. B. M. (Ed.), (2007). Architecture, Dhaka: Asiatic Society of Bangladesh. Cultural survey of Bangladesh series-2.

Imamuddin, A. H. and Longeteig, Karen R. (1990). Architectural \& Urban Conservation in the Islamic World, The Aga Khan Trust for Culture, Vol. 1. 
Imamuddin, A. H. (1993). Architectural Conservation Bangladesh, Asiatic Society of Bangladesh. Proceedings of the Seminar on Architectural Conservation.

Khondker, S. M. \& Tabassum, M. (2013). Kashinath Bhaban: A Unique Building of Panam Nagar Bears Testimony to Colonial Architecture in Bengal, IASET - International Journal of Civil Engineering (IJCE), 2(3), 97-108.

Khondker, S. M. (2013). Documentation on Five Colonial Buildings of Panam Nagar: Structure, Material, Decoration and Ornamentation, The AUST Journal of Science and Technology, 5(1), 1-23.

Khondker, S. M. \& Tabassum, M. (2018). Proposing a Conservation Management Plan for Bara Katra. Nakhara: Journal of Environmental Design and Planning, 14, 57-78.

Mowla, Q. A. \& Reza, M. (2000). Stylistic Evolution of Architecture in Bangladesh, Journal of the Asiatic Society of Bangladesh, 45(1), 31-58.
Mowla, Q. A. (2000). Colonial Urban Morphologies: an inquiry into typology and evolution pattern, Khulna University Studies, 2(1), 45-62.

Mowla, Q. A. (2008). Panam Nagar: Conservation and Management for Posterity.

Rahman S. M. (Ed.) (2007). Archeological Heritage, Dhaka: Asiatic Society of Bangladesh. Cultural survey of Bangladesh series-1.

Shaikh, Z. U. (2006). Adaptive Reuse and Development Guidelines for the Revitalization of Panam Nagar, [Unpublished], B. Arch dissertation prepared under the author at Bangladesh University of Engineering and Technology (BUET), Dhaka.

Shaikh, Z. U. \& Rahman M. (2009). Twenty Five BuildingsFrozen museum of Panam Nagar, Old but New: New but Old, Architectural Heritage Conservation, Rahman M. (Ed.), published by UNESCO. 


\section{旬}

CHITKARA

\section{Creative Space}

Chitkara University, Saraswati Kendra, SCO 160-161, Sector 9-C, Chandigarh, 160009, India

Volume 7, Issue 2

January 2020

ISSN 2321-3892

Copyright: [C 2020 Shirajom Monira Khondker and Nuzaba Binte Kabir] This is an Open Access article published in Creative Space (Creat. Sp.) by Chitkara University Publications. It is published with a Creative Commons Attribution- CC-BY 4.0 International License. This license permits unrestricted use, distribution, and reproduction in any medium, provided the original author and source are credited. 